\title{
Medical Student Perceptions of Integration of a Customized Cloud Based Learning Operating System into Problem Based Learning Tutorials
}

\author{
Rima Abdul Razzak ${ }^{1}$, Zuheir Hasan ${ }^{2}$ and Arpan Stephen ${ }^{1}$ \\ ${ }^{1}$ Arabian Gulf University (AGU), Manama, Bahrain \\ ${ }^{2}$ The Hashemite University, Zarqa, Jordan \\ reemala@agu.edu.bh \\ zuheirakh@hu.edu.jo \\ arpans@agu.edu.bh \\ DOI: 10.34190/EJEL.20.18.1.003
}

\begin{abstract}
Since its inception, the College of Medicine and Medical Sciences (CMMS) at the Arabian Gulf University (AGU) has adopted the problem based (PBL) pedagogy in Medicine relying on paper-based trigger material. However, delivery of such paper-based triggers during tutorial sessions was not optimal to promote medical student interactivity and engagement within tutorial sessions. As involvement of multimedia resources and tools in PBL are more valuable than simple print textual modes of learning and can have a positive impact on learning and knowledge integration, we aimed to digitize all our trigger material. Over the past three years CMMS has integrated after customization to PBL standards, the cloud-based operating system, UNIO into its problem-based learning (PBL) curriculum. The aim of UNIO integration was to digitize text triggers and enhance the quality of visual triggers in order to improve medical student interactivity and engagement within tutorial sessions. UNIO electronic platform was customized from a teacher-centered design to fit a PBL pedagogy. It was utilized to link student and tutor hardware within a group together for promoting interaction and collaborative learning. The effect of this teaching approach was evaluated from student responses to an in-house validated survey at the end of the fifth PBL module. Customization and integration of UNIO within the PBL curriculum resulted in an entirely paperless learning process. It created an integrated PBL system combining conventional text trigger in a digital form with digital media such as images, videos and other multimedia, while maintaining face-to-face setup. It also provided online and off -live access to content embedded at campus and open access to open source content online to both tutors and students. Results of the student satisfaction survey pointed to a predominantly neutral attitude towards integration of UNIO within our PBL tutorial sessions, but the item related to effectiveness of media triggers within UNIO received favorable responses from students. Further evaluation for a longer term is necessary for additional student feedback. Other forms of evaluation may be required in the aim of improvement and for justification of subsequent implementation of UNIO within our PBL curriculum.
\end{abstract}

Keywords: PBL, Medicine, Cloud-based learning, UNIO

\section{Introduction}

The College of Medicine and Medical Sciences (CMMS) at the Arabian Gulf University (AGU) in Bahrain has adopted since its establishment (35 years ago) the Problem-based learning (PBL) approach for teaching Medicine during phase II (Year 2 - 4 or pre-clerkship years) of the medical program. During this phase, students cover 92 health problems across 9 system-based units, with three units per year. Problem-based learning (PBL) is a student-centered educational approach, in which learning is based on authentic problems that are used as a vehicle to promote student learning of concepts (Barrows, 2002; Barrows and Tamblyn, 1980; Moust, Bouhuijs, and Schmidt, 2014). PBL is implemented in small face to face groups, while the tutors work as the facilitator of discussions among learners (Hung, Jonassen, and Liu, 2008). For PBL in Medicine, problems are presented to students in the form of a clinical health scenario. During their first tutorial session, both students and the facilitators are provided with a set of scenario-related learning triggers as the starting points of the PBL case. The students with the help of a facilitator discuss these triggers and generate the learning needs relevant to the health problem. These discussions foster learning by helping individual students to activate prior knowledge, to elaborate, and to stimulate the re-structuring of knowledge (Moust, Bouhuijs, and Schmidt, 2014). During the second tutorial session, the students review, discuss and present what they have learned during the week.

Up to three years ago, CMMS has embraced the traditional paper - based PBL, and the use of technology in PBL was limited and sedated. The relatively recent adoption of technology into PBL was driven by stakeholders 
including the college administration, students and tutors. The aim of the college administration was to comply with the university's initiative for integrating e-learning within some curricula and optimal utilization of the technology resources in which the university has invested heavily. Students' evaluation of paper - based PBL over the past few previous years has consistently pointed to student demands for introducing more technology into their educational activities. This is anticipated from the IT savvy students who have grown up with technology and expect to learn through its application in their PBL experience. Other challenges of paper - based trigger material that students described include the inadequate quality and resolution of some hardcopy visual triggers, the lack of access to them after the tutorial sessions and the larger quantity of paperbased course material and ineffective organization of their paper resources.

Tutors were mainly concerned with students' capacity for interaction and engagement during tutorial sessions. Hard - copy text triggers were presented to each student as paragraphs on one or two pages during the first tutorial session, and students could access triggers consequent to that in discussion. Complete exposure of the triggers eliminated any eagerness or imagination about the next trigger. Additionally, delivery of the paperbased visual triggers (Imaging scans, X-rays, histopathology slides, etc...) was inefficient, as students passed them from one to another and scrutinized them individually. Some students felt isolated and distracted from other group members and there was a lack of group focus in general. For tutors, this did not seem effective for students to achieve their learning needs as gradual unfolding and collaborative examination of triggers would be.

\section{Literature Review}

Over the past years, there has been increasing interest of integration of technology and application of multimedia to support PBL in medicine. The active and independent learning required and involved in PBL can be improved by the introduction of technology and multimedia, for they can offer media-saturated students a wide network of information and interactive simulations necessary to enrich the PBL process. In a systemic review of 28 studies on the effect of educational technologies in problem-based learning in health sciences education, Jin and Bridges (2014) listed some positive outcomes of integration of technology into PBL for student learning. These include providing rich, authentic problems and/or case contexts for learning, supporting student development of medical expertise through the accessing and structuring of expert knowledge and skills, and reducing perceived cognitive load.

The educational technologies that have been adopted to support problem-based approaches to learning include innovations such as learning management system (LMS), specialist learning software (e.g., CMapTools), immersive virtual environments (e.g., SecondLife), and resources such as 3-dimensional (3D) anatomy models and other forms of multimedia. PBL problems that are enriched with multimedia support contextual learning (Hung, Jonassen, and Liu, 2008; Bridges et al., 2012) and are more engaging and authentic than problems based on text alone and can have a positive impact on problem solving and learning, resulting in improved knowledge integration (Price Kerfoot, Masser and Hafler, 2005). This is the reason why most PBL programs use multimedia for the presentation of triggers for the problems in addition to the trigger text, as they enhance students' observation skills, and provide them with new information to add to the cues obtained from the trigger text.

An example of a success story is the EDIT project at the Faculty of Health Sciences at Linkoping University in Sweden, in which web-based multimedia-enhanced scenarios replaced text-based PBL scenarios (Personn, Fyrenius and Bergdahl, 2010). The introduction of the web-based scenarios had positive effects in that it made the group more focused and did not have any long-term negative effects on the group dynamics. Other examples of enriching PBL problems in Medicine with multimedia is the use of virtual patients and interactive patient cases which allows students to practice clinical reasoning in real life-like ways (Savin-Baden et al., 2010, 2011). Some studies relied on simulations, and the traditional PBL tutorial group meetings were alternated with sessions with a "Human Patient Simulator" in the simulation center (Harris, Ryan and Rabuck, 2012).

Educational technology can be used in PBL to support learners through the problem solving process by providing tools and resources; for instance, installation of large screen displays with Internet access has shown positive impact on tutorials at Harvard (Price Kerfoot, Masser and Hafler, 2005). Other uses have included networked computers to support tutorial groups (Koschmann et al, 1996). Additionally, the use of new 
hardware, such as interactive whiteboards (IWBs) in synchronous face-to-face PBL has reshaped new forms of learning (Bridges, Botelho and Tsang 2010, Bridges et al., 2012; Beeland, 2002).

We digitized our PBL process by utilizing pre-existing technology resources available at CMMS to a fuller capacity and customizing an electronic cloud based learning operating platform, UNIO, keeping in mind that such technology integration must support and preserve the basic principles of PBL. We aimed to explore students' satisfaction with incorporating technology into their problem-based learning through a survey measuring the efficacy of UNIO in teaching the students and the students' interaction with it.

\section{Method}

Faculty participants in the PBL process at CMMS were either holders of a doctorate degree in basic medical science or clinicians academically affiliated with the college. Student participants were medical students at CMMS in their pre-clerkship phase (Year 2) and had completed two PBL units so far.

The aims of this study are to:

- Explain briefly the customization process of the teacher-centered cloud-based platform, UNIO, and its integration within the PBL tutorials in Medicine at CMMS.).

- Describe how through employment of pre-existing technology at CMMS, UNIO produced and presented a combination of digitized text triggers and other multimedia like graphics, sound, animation and video, as part of the weekly health problem.

- Provide first-time evaluation of student perception on integrating UNIO into the PBL tutorial sessions and its effectiveness for active learning.

\subsection{Integration of UNIO into PBL tutorials}

The electronic learning operating system, UNIO was adopted by CMMS at AGU in 2016 as an educational tool in PBL with the consent of CMMS Medical Curriculum Committee and higher authorities of the college and university. UNIO is a Cloud based electronic Learning Operating System developed by the award-winning Harness Handitouch UK Private Limited (London, UK). It is device and browser agnostic, and its many great features (Table 1) for effective learning created the opportunity for its integration within the PBL system.

Table 1: Features of the original platform UNIO before customization to PBL principles

\begin{tabular}{ll}
\hline & \multicolumn{1}{c}{ Features of UNIO } \\
\hline- & Paperless \\
- & Teacher-centered learning \\
- & Introduces live, versatile white-boarding \\
- & Independent student annotations as a separate layer \\
- & Embedding of various form of content \\
- & On-campus and off-campus access to organized course material \\
\hline
\end{tabular}

\subsubsection{Tutorial group linkage}

Each group carried out their PBL tutorial sessions in designated classes equipped with a smartboard, a computer and proper seating. Each tutor was also provided with an IPAD for their tutorial session. The elearning experts at CMMS were responsible for the technical integration of UNIO into tutorials. UNIO allowed for mapping of all members of a tutorial group together and linking by network media of all members within a tutorial group, including the tutor.

\subsubsection{Embedding of PBL tutorial content}

Problems for each unit were embedded and organized by problem title. Sub-titles of other content for each tutorial session were also added to allow easy student access and localization of required content (figure 1). 


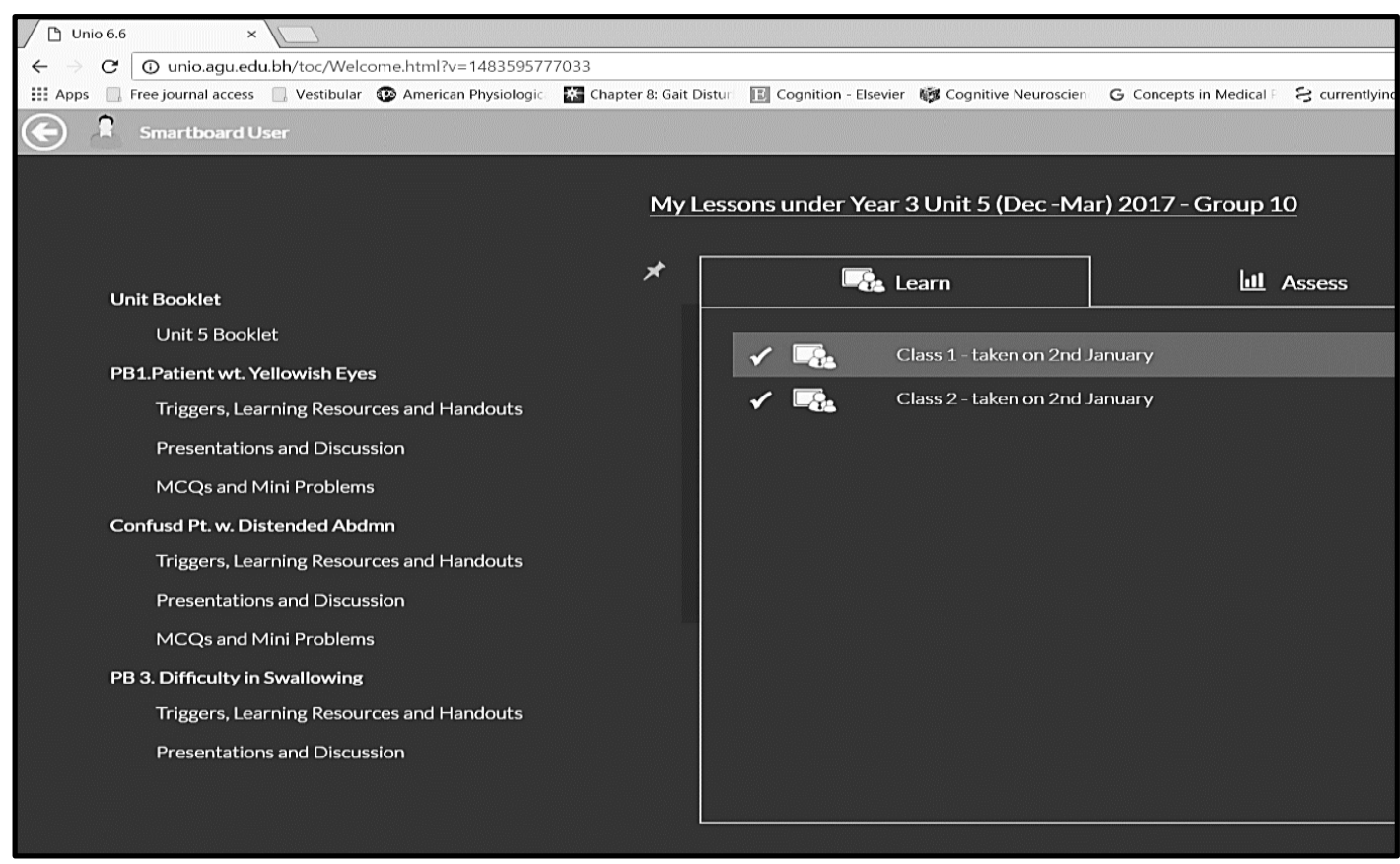

Figure 1: Screen capture of the web-based platform page when accessing a course/unit after login into UNIO

The tutor guide for the weekly problem within each unit was embedded by the e-learning expert two days before the first session of the tutorial. Embedded content associated with the problem included text triggers, student-tutor interactions, graphics, multimedia, radiology images, lab reports (figure 2), and learning resources such as textbooks and relevant Internet links. Tutors could also embed extra content they may feel necessary before, during and after the tutorial sessions. Students were given permission to embed content from the internet during the tutorial sessions.

a)

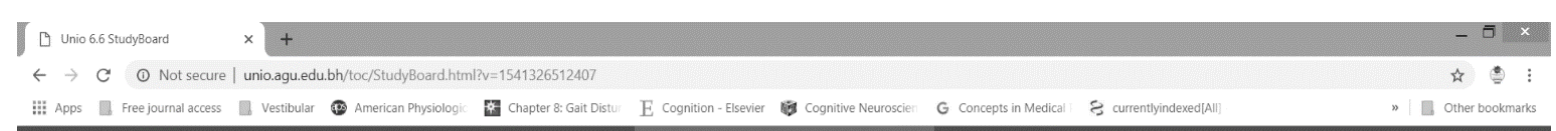

4] 11 , It Triggers, Learning Resources...

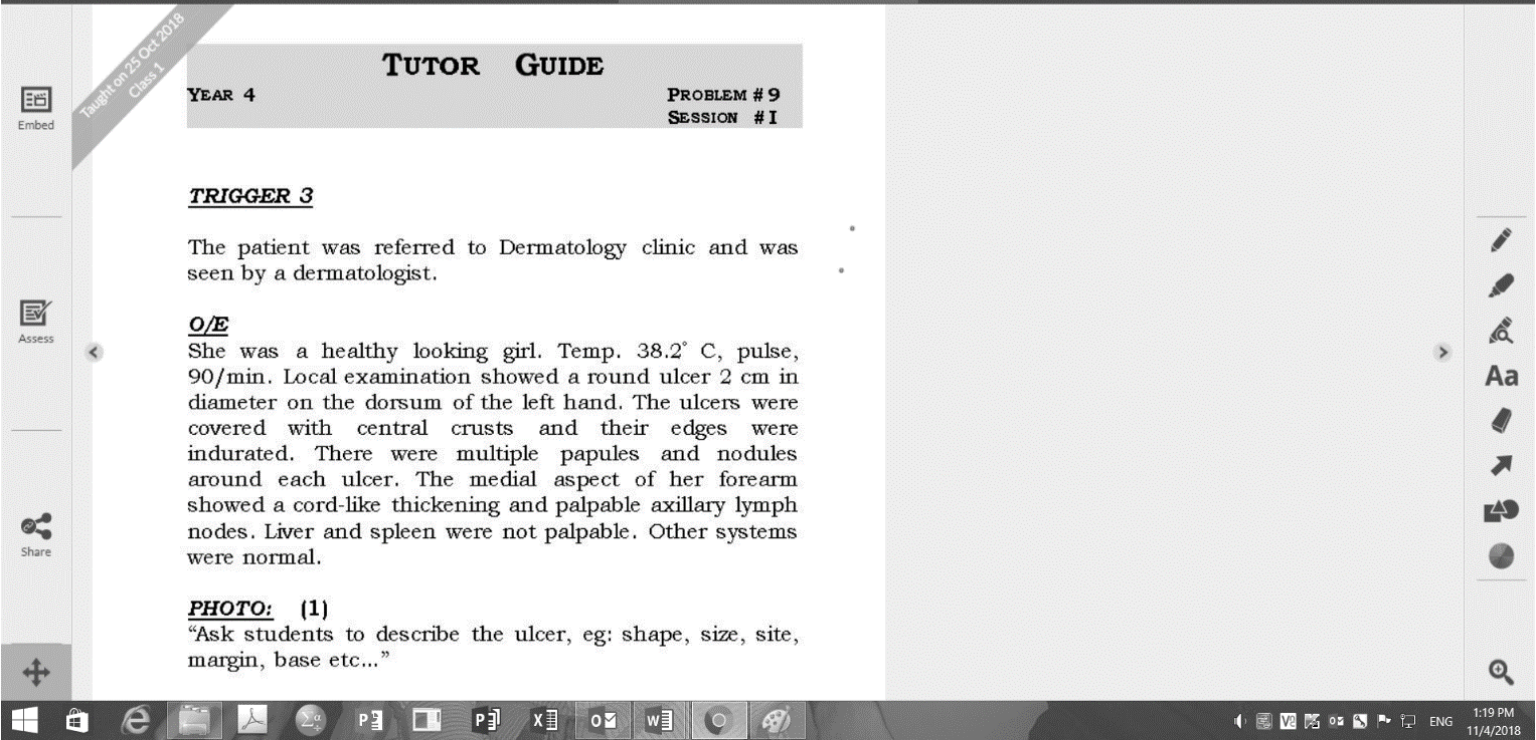


b)

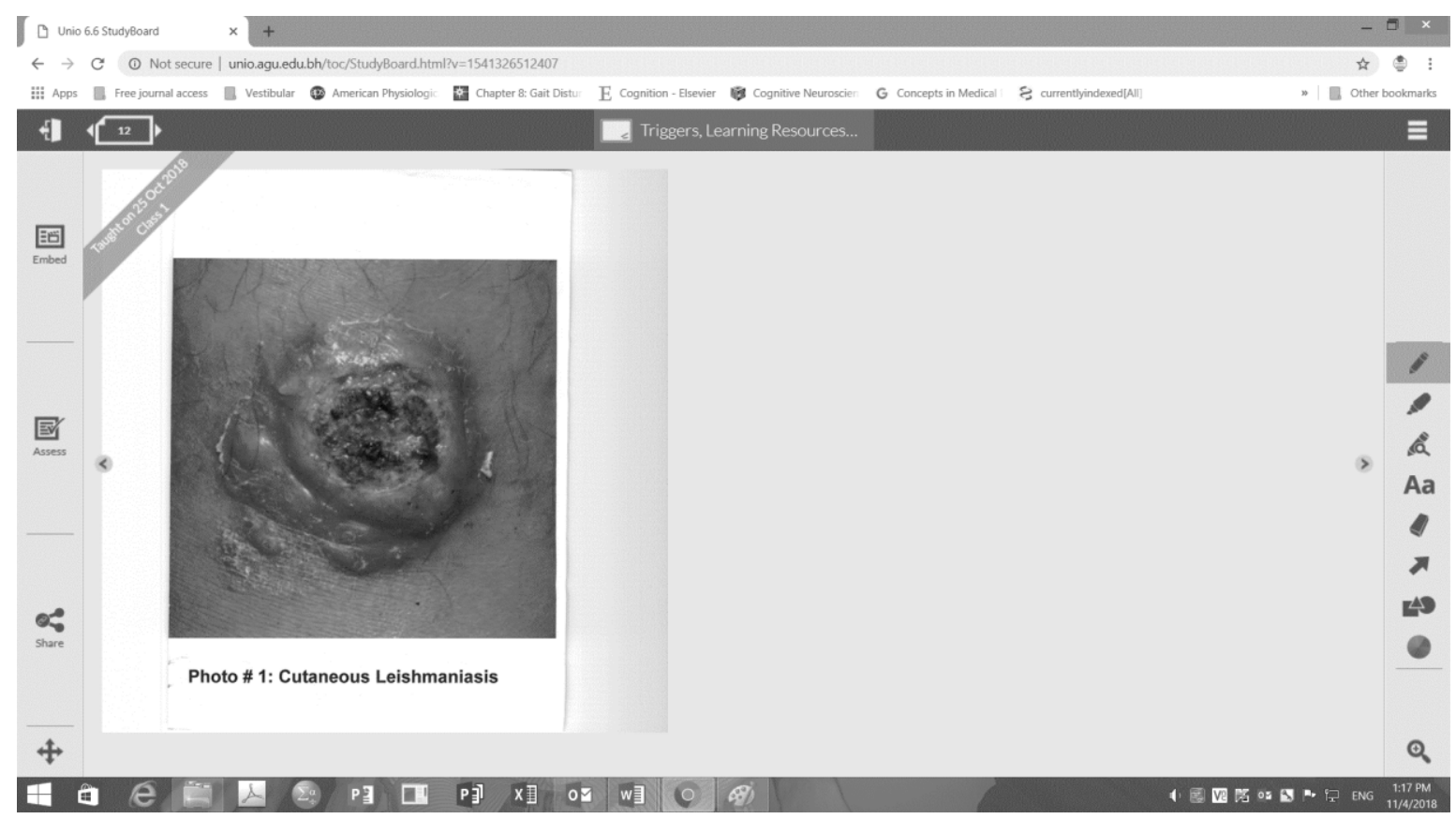

c)

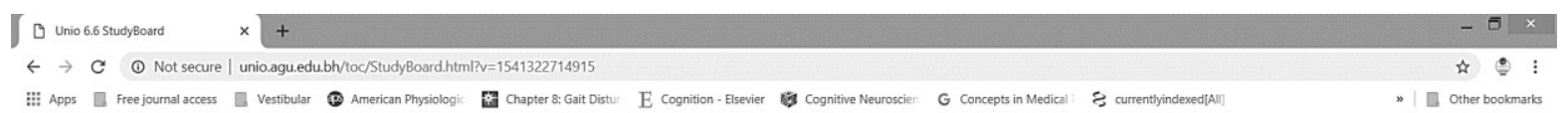

4] 8 (a) Triggers, Learning Resources...

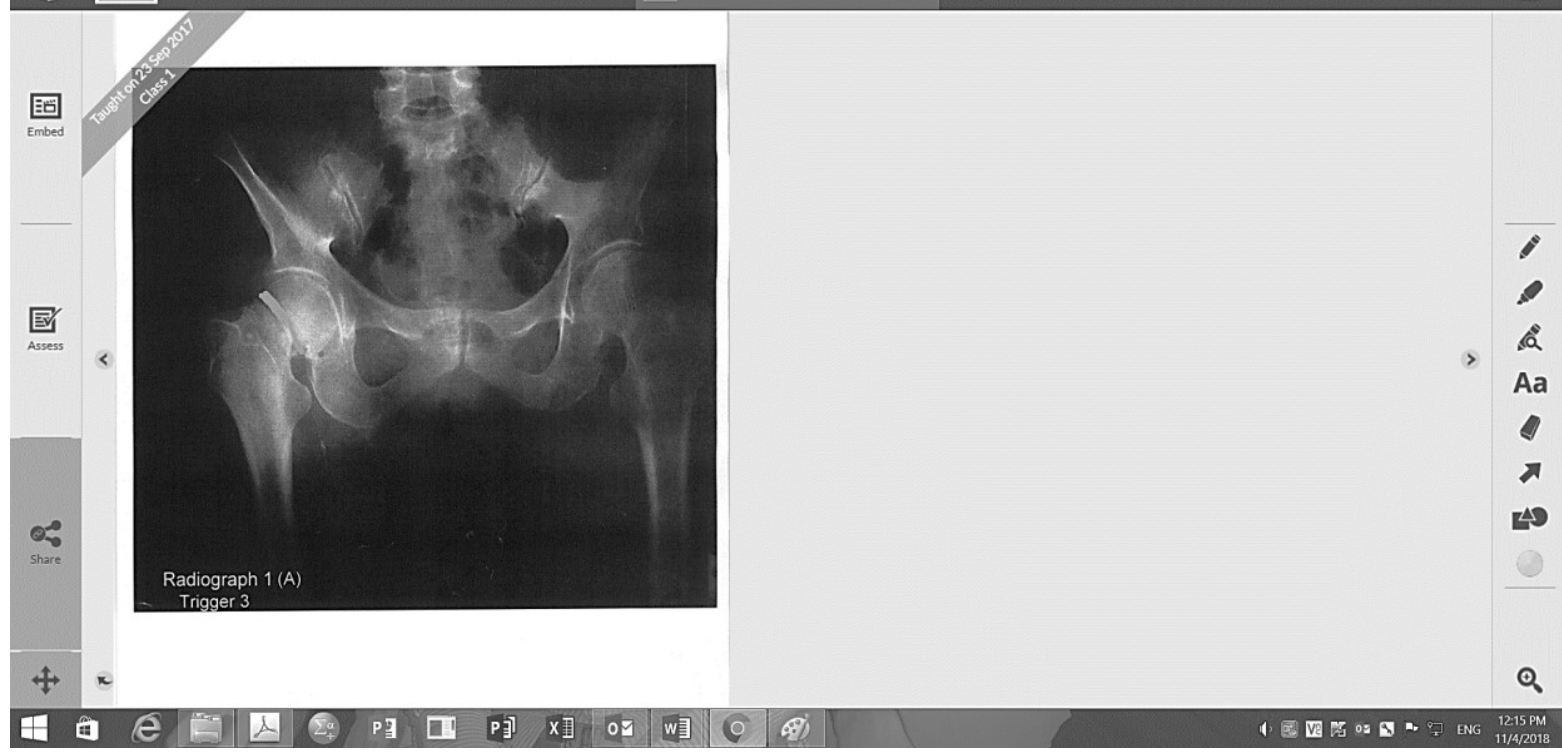

Figure 2: Screen capture of a) embedded text trigger on a single page, b) photo associated with the trigger (trigger 3 in (a)) embedded on a separate page and c) an example of embedded radiology image

A useful feature of UNIO is the annotation capacity. For each problem, every trigger was embedded on a separate UNIO page to allow for gradual revealing of triggers and annotations by students or the scribe (Smart board user) (figure 3). 
a)

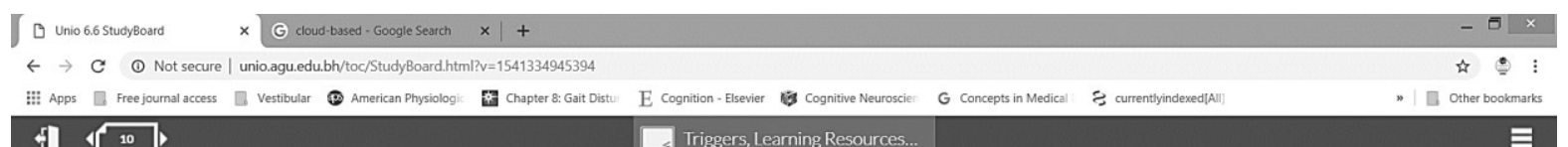

4] 10 (1) Triggers, Learning Resources...

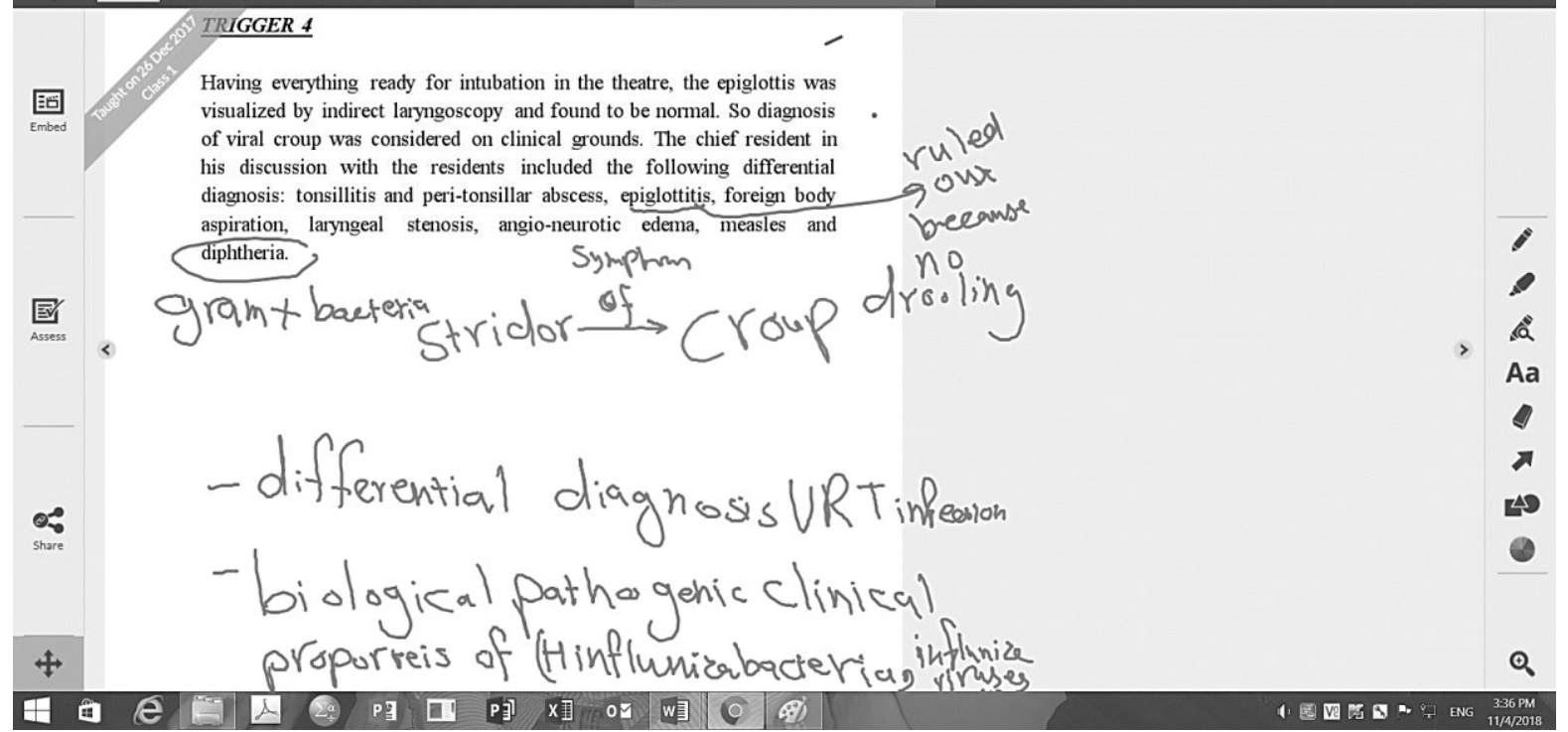

b)

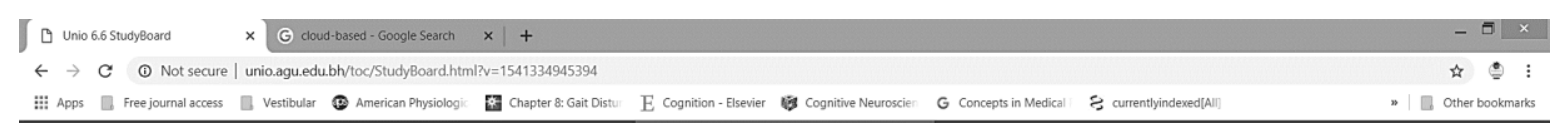

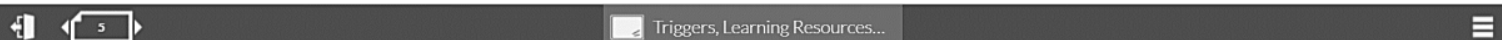

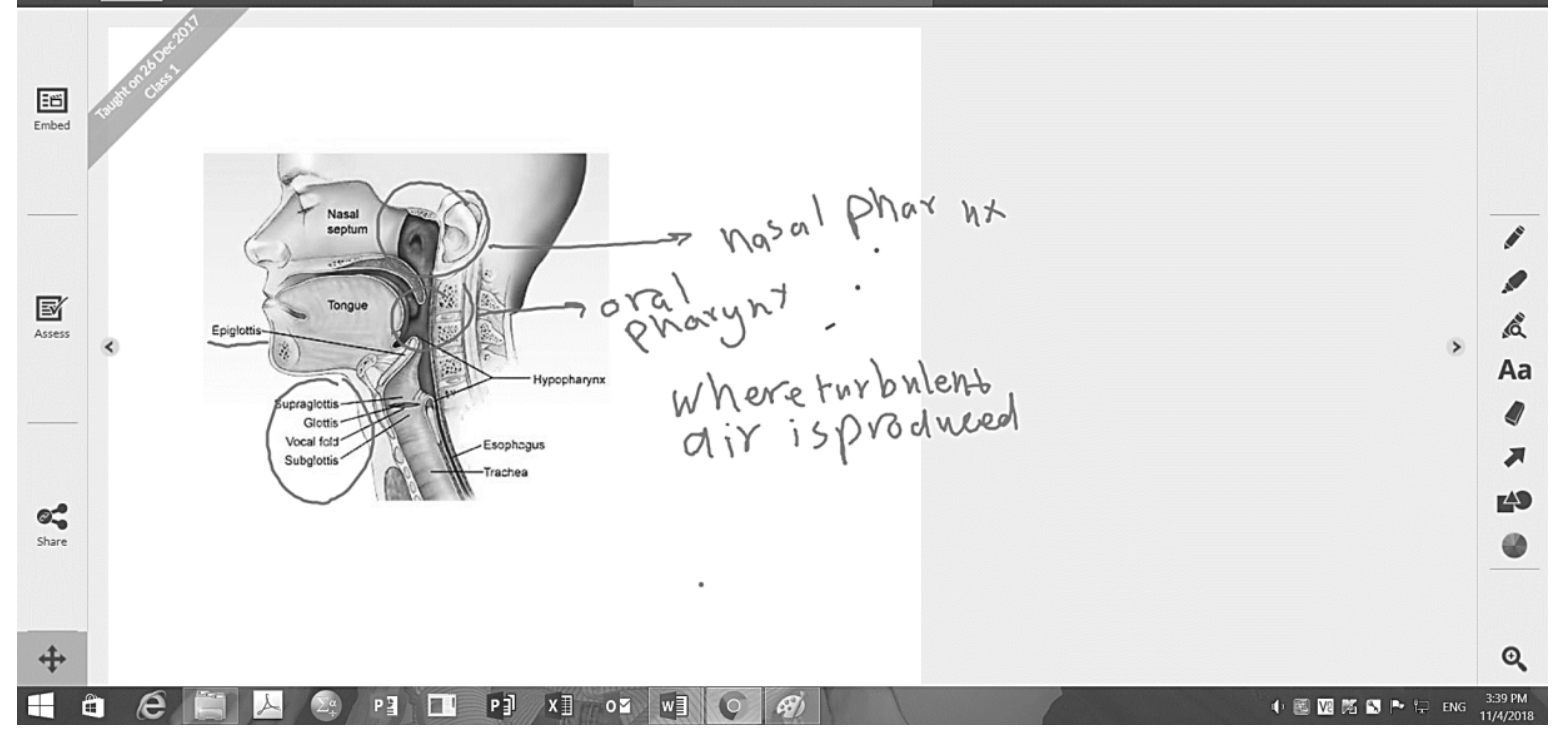

Figure 3: Screen capture showing annotations on a) trigger text or b) embedded visual trigger such as images by the scribe on the smartboard. These annotations are automatically broadcasted to devices of all students within the tutorial group.

\subsubsection{Customization of UNIO}

We took into consideration how crucial the design of an e-learning platform is to the students' success (Reeves, 1998; Liaw, 2008; Lu and Chiou, 2010) and how it dictates levels of their engagement and interactivity in a PBL setting (Verstegen et al., 2016). The challenge with UNIO was that it was originally designed as a teacher-centered system with a lecture-based set-up, so considerable customization was requested from the developers to transform it for CMMS to maintain the PBL setting and principles. Many features were added, and below is a brief description of such features. 
- "PRESENTER" feature. For each tutorial group, the e-learning experts have created an extra account for a virtual student known as "Smartboard User". This account is designated for the scribe to utilize on the smartboard and log into UNIO with his/her tutorial group. The tutor assigns "PRESENTER" to the Smartboard User, so that whatever actions are carried out by the scribe (Presenter) at the smartboard is broadcasted to all students and tutor in that group.

- "EXPORT" feature was a specific customization by request from students. Students can now export the entire content including all annotations made during the tutorial session in a PDF format and directly send it to any email account or print it.

- "ZOOM" feature is very beneficial when students want a close-up of embedded content.

- "HIDE CONTENT/REVEAL CONTENT" feature. The e-Learning expert embedded the problem tutor guide on a weekly basis with the student-tutor interactions already hidden for the student, but visible to the tutor. Students cannot reveal any of the hidden content (figure 4).

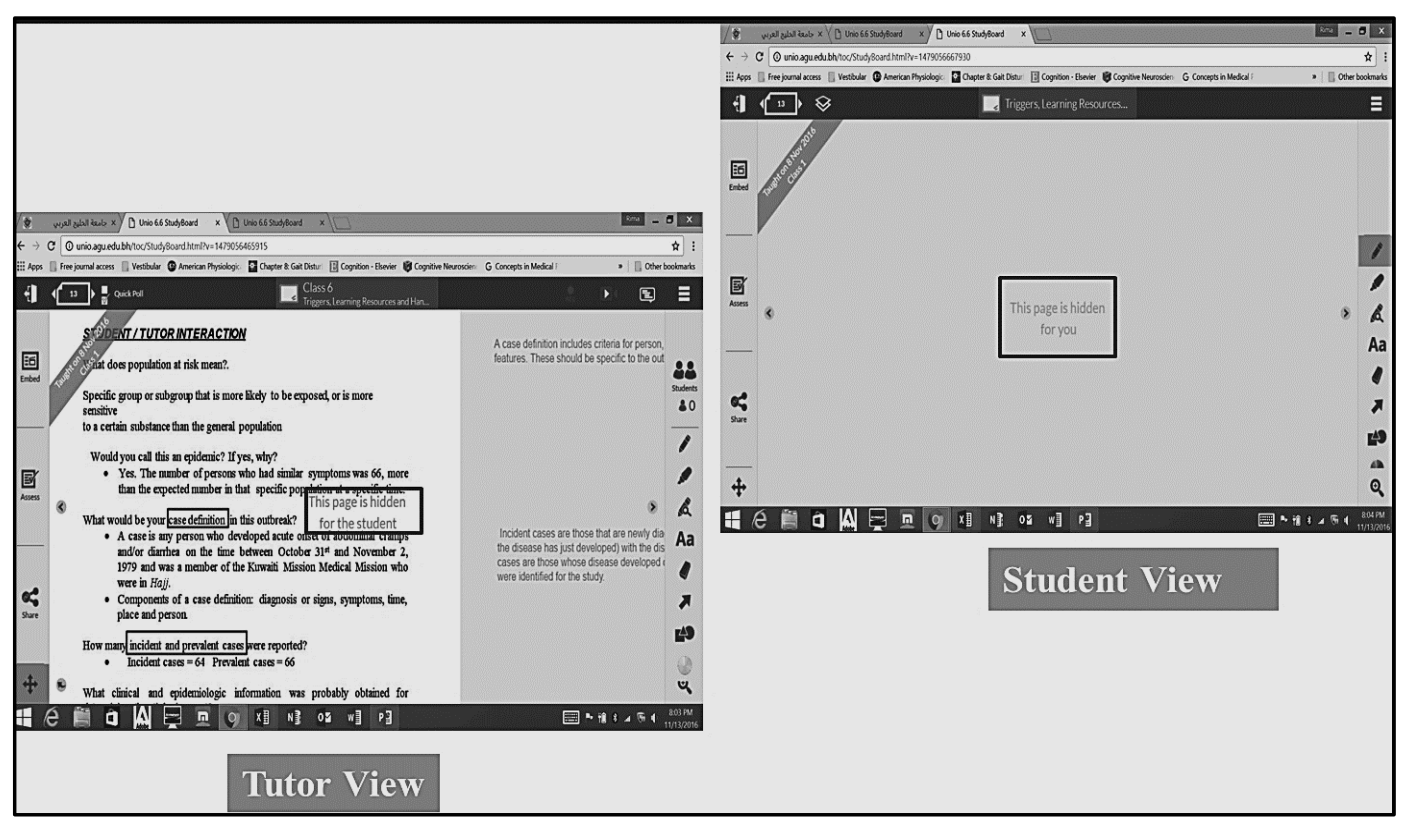

Figure 4: Screen capture of student-tutor interactions and tutor personal notes on the tutor's I-Pad. These are hidden from all students within the group (Student View).

\subsection{Survey instruments and dissemination}

The anonymous student survey consisted of 25 questions that included Likert-type scale questions that evaluated students' attitudes towards the integration of UNIO into PBL. The student survey was designed to assess four major domains: 1) the technical aspects of UNIO, 2) its effectiveness in PBL, 3) preparation for exams, 4) ease of application, and overall opinion of the electronic platform UNIO. The survey was paperbased and distributed to students and gathered by personnel from the Quality Assurance and Excellence Center (QAEC) at AGU. Students were assured of anonymity and were not asked to disclose any personal information. There were no incentives offered for completing the survey.

The Likert Scale used was a 5-point scale that offers a range of response options, from one extreme attitude to another, like "Strongly Agree" to "Strongly Disagree." They also included a neutral midpoint. Values (points) were also assigned for each response as: Strongly Agree $=5$ points; Agree $=4$ points; Neutral $=3$ points; Disagree $=2$ points; Strongly Disagree $=1$ point. These values were used to report a single average response for each item. The percentages of students responding with a score value were also calculated for each item. 


\section{Findings}

118 out of 202 students (58.5\%) responded to the survey. Table 2 shows that a neutral score (Score 3) was given for most items, indicating that students were not yet decisive about their satisfaction level. $30 \%-40 \%$ of students were neutral to every survey item as shown in figure 5 . The original scoring weights gives "Neutral" a " 3 " scoring weight meaning more than disagreement but less than agreement, but does not represent an intermediary answer between disagreement and agreement. To compensate for this, we aimed to determine how the respondents generally leaned for each item. Accordingly, we assigned a 5-point scale that offered the response options with the following coding (values): "Strongly Agree" = 2 points, "Agree" = 1 point, "Neutral" = 0 points "Disagree" = -1 point and "Strongly Disagree" = -2 points. These points were used to report a single total response and determine the direction of the response for each item (Table 3).

Table 2 shows that students reported a satisfaction score bordering on " 3 " on the 5-point Likert scale on most items, which indicates an almost $60 \%$ satisfaction rate for most items. Similarly, Table 3 reveals a general positive lean for most items. There was concordance between the two methods in the responses to most items, with scores of less than " 3 " corresponding to negative directions. Five items scored lower than " 3 ", with the least score of 2.88 and a corresponding most negative value of -14 for item 13, which is related to students' belief that UNIO made their study style better and UNIO's efficacy to help students prepare for their exams. Another negative result was related to the difficulty students encountered in uploading images into UNIO pages and their skills with UNIO throughout subsequent units.

The highest scores were in the section exploring the effectiveness of UNIO in PBL. Students were most satisfied with integration of media triggers as a mean to increase their ability to identify their learning needs and with the embedding of extra online content during tutorial sessions to help them understand difficult and abstract concepts. These items received a score of 3.23 and 3.21 respectively corresponding to highest positive values of 27 and 25 respectively. Students were also in favor of UNIO enhancing in-class group learning and facilitating interaction. Organization of the learning triggers and other learning materials and the Zoom feature received favorable ratings as well. 
Table 2: Student responses to survey items as average score for each item

\begin{tabular}{|c|c|c|}
\hline \multicolumn{2}{|c|}{ Item Number } & \multirow[t]{2}{*}{$\begin{array}{c}\text { Average } \\
\text { Score }\end{array}$} \\
\hline & Technical & \\
\hline Item 1 & I had no technical problems in accessing the platform. & $3.06 \pm 1.39$ \\
\hline Item 2 & The UNIO platform is user friendly. & $3.14 \pm 1.27$ \\
\hline \multirow[t]{2}{*}{ Item 3} & Accessing course materials off campus through UNIO was easy. & $3.16 \pm 1.27$ \\
\hline & Effectiveness in PBL & \\
\hline Item 4 & UNIO enhances my ability to write and organize my learning needs. & $3.12 \pm 1.25$ \\
\hline Item 5 & UNIO enhances in-class group learning. & $3.20 \pm 1.26$ \\
\hline Item 6 & UNIO facilitates student- tutor interaction and group discussion. & $3.16 \pm 1.29$ \\
\hline Item 7 & $\begin{array}{l}\text { Presenting the embedded content and annotating on the smartboard keeps me engaged with others in the } \\
\text { group. }\end{array}$ & $3.18 \pm 1.25$ \\
\hline Item 8 & Integration of media triggers (images, X-rays....) into UNIO increases my ability to identify the learning needs. & $3.23 \pm 1.22$ \\
\hline Item 9 & $\begin{array}{l}\text { During tutorial sessions, embedding of extra online content into UNIO could help students understand difficult } \\
\text { concepts. }\end{array}$ & $3.21 \pm 1.22$ \\
\hline Item 10 & The use of UNIO and electronic learning is preferable to me than the paper-based method for the tutorials. & $3.07 \pm 1.21$ \\
\hline \multirow[t]{2}{*}{ Item 11} & $\begin{array}{l}\text { UNIO is also very effective for whole-class teaching such as real-time discussion/solving difficult concepts } \\
\text { like "Renal Clearance". }\end{array}$ & $3.10 \pm 1.10$ \\
\hline & Preparation for Exams & \\
\hline Item 12 & $\begin{array}{l}\text { The UNIO enhances my ability to organize my learning material and enhances my preparation for the end unit } \\
\text { examination. }\end{array}$ & $3.10 \pm 1.22$ \\
\hline Item 13 & I believe my study style is better with use of UNIO and its application. & $2.88 \pm 1.21$ \\
\hline Item 14 & Preservation of in-class annotations by UNIO is useful for future referencing and studying for BSc. exam. & $3.0 \pm 1.18$ \\
\hline \multirow[t]{2}{*}{ Item 15} & $\begin{array}{l}\text { Off-campus access to UNIO without losing embedded content is beneficial for my weekly studying and exam } \\
\text { preparation. }\end{array}$ & $3.03 \pm 1.23$ \\
\hline & Application & \\
\hline Item 16 & Units, learning triggers and other problem related material are well organized in UNIO. & $3.18 \pm 1.20$ \\
\hline Item 17 & The "Zoom" feature of UNIO is very useful during the tutorial sessions. & $3.18 \pm 1.27$ \\
\hline Item 18 & The "Export" feature of UNIO is an efficient way of sharing and printing the lesson content. & $3.04 \pm 1.22$ \\
\hline Item 19 & I use UNIO to annotate my personal notes during the tutorial session. & $2.92 \pm 1.21$ \\
\hline Item 20 & The quality of the media embedded as part of the weekly problems into UNIO is adequate. & $3.04 \pm 1.15$ \\
\hline Item 21 & Uploading images is easy with UNIO. & $2.90 \pm 1.20$ \\
\hline \multirow[t]{2}{*}{ Item 22} & UNIO enhances my learning capacity during tutorials. & $2.95 \pm 1.16$ \\
\hline & Overall & \\
\hline Item 23 & The learning activities during the tutorials could be performed easily with the UNIO. & $2.97 \pm 1.19$ \\
\hline Item 24 & $\begin{array}{l}\text { I think that my skills in using UNIO have improved throughout subsequent units and I am now convinced that } \\
\text { UNIO is a good instructional tool and effective for learning. }\end{array}$ & $3.03 \pm 1.23$ \\
\hline Item 25 & Overall I am satis fied with this platform. & $3.03 \pm 1.13$ \\
\hline
\end{tabular}

Student agreement to each of the items was assessed using a 5-point Likert scale: 1 - Strong disagreement; 2 Disagreement; 3 - Neutral; 4- Agreement; 5 - Strong agreement. The values represent mean \pm SD. 
Technical
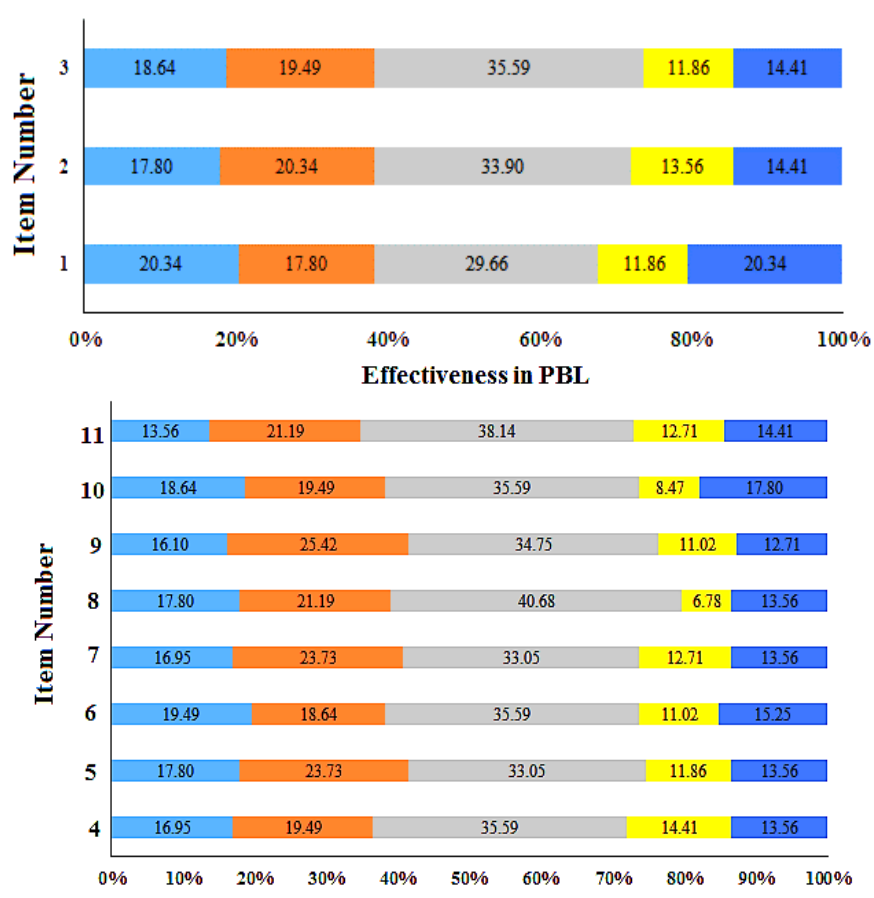

Preparation For Exams

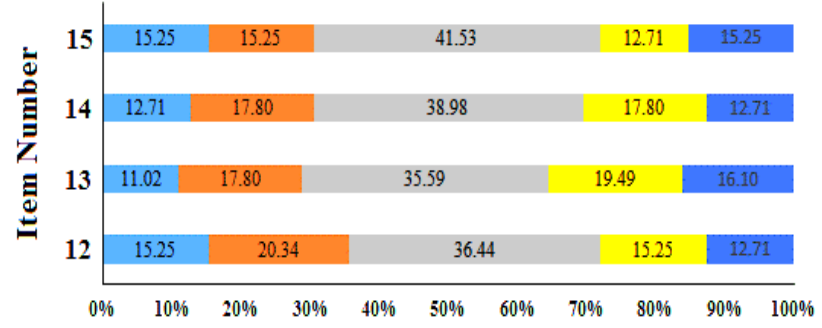

Application
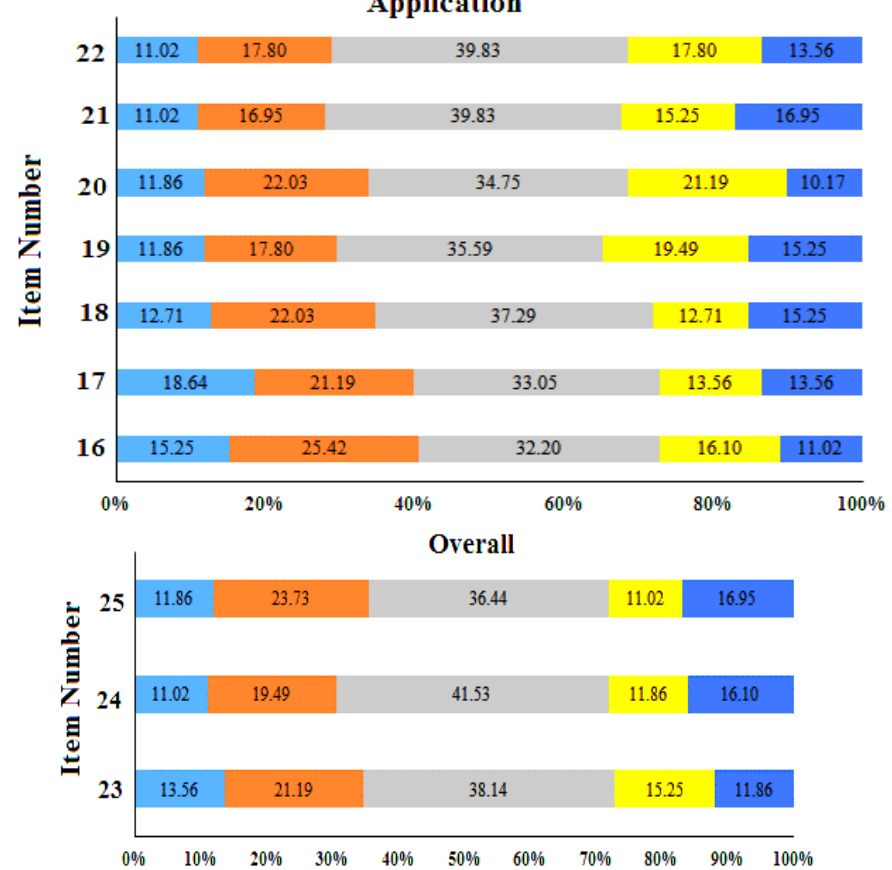

$\|$ Strongly Agree (\%) $\backsim$ Agree (\%) $\backsim$ Neutral (\%) $\backsim$ Disagree (\%) $\backsim$ Strongly Disagree (\%)

Figure 5: Stacked bar graph representation of data for all items in the student satisfaction survey 
Table 3: Evaluation of perception of students towards integration of UNIO into PBL while only considering the non-neutral responses

\begin{tabular}{|c|c|c|c|c|c|c|c|c|c|c|c|}
\hline $\begin{array}{l}\text { Item } \\
\text { Number }\end{array}$ & & $\begin{array}{c}\text { Strongly } \\
\text { Agree } \\
(+2)\end{array}$ & $\begin{array}{c}\text { Agree } \\
(+1)\end{array}$ & $\begin{array}{c}\text { Neutral } \\
\text { (0) }\end{array}$ & $\begin{array}{c}\text { Disagree } \\
(-1)\end{array}$ & $\begin{array}{l}\text { Strongly } \\
\text { Disagree } \\
(-2)\end{array}$ & $\begin{array}{l}\text { Strongly } \\
\text { Agree } \\
\text { Weighted }\end{array}$ & $\begin{array}{c}\text { Agree } \\
\text { Weighted }\end{array}$ & $\begin{array}{c}\text { Disagree } \\
\text { Weighted }\end{array}$ & $\begin{array}{l}\text { Strongly } \\
\text { Disagree } \\
\text { Weighted }\end{array}$ & Total \\
\hline & Technical & & & & & & & & & & \\
\hline Item 1 & I had no technical problems in accessing the platform. & 24 & 21 & 35 & 14 & 24 & 48 & 21 & -14 & -48 & 7 \\
\hline Item 2 & The UNIO platform is user friendly. & 21 & 24 & 40 & 16 & 17 & 42 & 24 & -16 & -34 & 16 \\
\hline \multirow[t]{2}{*}{ Item 3} & Aocessing course materials off campus through UNIO was easy. & 22 & 23 & 42 & 14 & 17 & 44 & 23 & -14 & -34 & 19 \\
\hline & \multicolumn{11}{|l|}{ Effectiveness in PBL } \\
\hline Item 4 & $\begin{array}{l}\text { UNIO enhances my ability to write and organize my learning } \\
\text { needs. }\end{array}$ & 20 & 23 & 42 & 17 & 16 & 40 & 23 & -17 & -32 & 14 \\
\hline Item 5 & UNIO enhances in-class group learning. & 21 & 28 & 39 & 14 & 16 & 42 & 28 & -14 & -32 & 24 \\
\hline Item 6 & UNIO facilitates student- tutor interaction and group discussion. & 23 & 22 & 42 & 13 & 18 & 46 & 22 & -13 & -36 & 19 \\
\hline Item 7 & $\begin{array}{l}\text { Presenting the embedded content and annotating on the } \\
\text { smartboard keeps me engaged with others in the group. }\end{array}$ & 20 & 28 & 39 & 15 & 16 & 40 & 28 & -15 & -32 & 21 \\
\hline Item 8 & $\begin{array}{l}\text { Integration of media triggers (images, X-rays....) into UNIO } \\
\text { increases my ability to identify the learning needs. }\end{array}$ & 21 & 25 & 48 & 8 & 16 & 42 & 25 & -8 & -32 & 27 \\
\hline Item 9 & $\begin{array}{l}\text { During tutorial sessions, embedding of extra online content into } \\
\text { UNIO could help students understand difficult concepts. }\end{array}$ & 19 & 30 & 41 & 13 & 15 & 38 & 30 & -13 & -30 & 25 \\
\hline Item 10 & $\begin{array}{l}\text { The use of UNIO and electronic learning is preferable to me than } \\
\text { the paper-based method for the tutorials. }\end{array}$ & 22 & 23 & 42 & 10 & 21 & 44 & 23 & -10 & -42 & 15 \\
\hline \multirow[t]{2}{*}{ Item 11} & $\begin{array}{l}\text { UNIO is also very effective for whole-dass teaching such as real- } \\
\text { time discussion/solving difficult concepts like "Renal } \\
\text { Clearance". }\end{array}$ & 16 & 25 & 45 & 15 & 17 & 32 & 25 & -15 & -34 & 8 \\
\hline & \multicolumn{11}{|l|}{ Preparation for Exams } \\
\hline Item 12 & $\begin{array}{l}\text { The UNIO enhances my ability to organize my learning material } \\
\text { and enhances my preparation for the end unit examination. }\end{array}$ & 18 & 24 & 43 & 18 & 15 & 36 & 24 & -18 & -30 & 12 \\
\hline Item 13 & $\begin{array}{l}\text { I believe my study style is better with use of UNIO and its } \\
\text { application. }\end{array}$ & 13 & 21 & 42 & 23 & 19 & 26 & 21 & -23 & -38 & -14 \\
\hline Item 14 & $\begin{array}{l}\text { Preservation of in-dass annotations by UNIO is useful for future } \\
\text { referencing and studying for BSc. exam. }\end{array}$ & 15 & 21 & 46 & 21 & 15 & 30 & 21 & -21 & -30 & 0 \\
\hline Item 15 & $\begin{array}{l}\text { Off-campus access to UNIO without losing embedded content is } \\
\text { beneficial for my weekly studying and exam preparation. }\end{array}$ & 18 & 18 & 49 & 15 & 18 & 36 & 18 & -15 & -36 & 3 \\
\hline & \multicolumn{11}{|l|}{ Application } \\
\hline Item 16 & $\begin{array}{l}\text { Units, learning triggers and other problem related material are } \\
\text { well organized in UNIO. }\end{array}$ & 18 & 30 & 38 & 19 & 13 & 36 & 30 & -19 & -26 & 21 \\
\hline Item 17 & $\begin{array}{l}\text { The "Zoom" feature of UNIO is very useful during the tutorial } \\
\text { sessions. }\end{array}$ & 22 & 25 & 39 & 16 & 16 & 44 & 25 & -16 & -32 & 21 \\
\hline Item 18 & $\begin{array}{l}\text { The "Export" feature of UNIO is an efficient way of sharing and } \\
\text { printing the lesson content. }\end{array}$ & 15 & 26 & 44 & 15 & 18 & 30 & 26 & -15 & -36 & 5 \\
\hline Item 19 & $\begin{array}{l}\text { I use UNIO to annotate my personal notes during the tutorial } \\
\text { session. }\end{array}$ & 14 & 21 & 42 & 23 & 18 & 28 & 21 & -23 & -36 & -10 \\
\hline Item 20 & $\begin{array}{l}\text { The quality of the media embedded as part of the weekly problems } \\
\text { into UNIO is adequate. }\end{array}$ & 14 & 26 & 41 & 25 & 12 & 28 & 26 & -25 & -24 & 5 \\
\hline Item 21 & Uploading images is easy with UNIO. & 13 & 20 & 47 & 18 & 20 & 26 & 20 & -18 & -40 & -12 \\
\hline \multirow[t]{2}{*}{ Item 22} & UNIO enhances my learning capacity during tutorials. & 13 & 21 & 47 & 21 & 16 & 26 & 21 & -21 & -32 & -6 \\
\hline & \multicolumn{11}{|l|}{ Overall } \\
\hline Item 23 & $\begin{array}{l}\text { The learning activities during the tutorials could be performed } \\
\text { easily with the UNIO. }\end{array}$ & 16 & 25 & 45 & 18 & 14 & 32 & 25 & -18 & -28 & 11 \\
\hline Item 24 & $\begin{array}{l}\text { I think that my skills in using UNIO have improved throughout } \\
\text { subsequent units and I am now convinced that UNIO is a good } \\
\text { instructional tool and effective for learning. }\end{array}$ & 13 & 23 & 49 & 14 & 19 & 26 & 23 & -14 & -38 & -3 \\
\hline Item 25 & Overall I am satisfied with this platform. & 14 & 28 & 43 & 13 & 20 & 28 & 28 & -13 & -40 & 3 \\
\hline
\end{tabular}

"Weighted" refers to the response code value $(-2$ to +2$)$ multiplied by the number of responses in each response category. Total is the sum of the weighted responses.

\section{Discussion and conclusions}

The current study describes briefly the customization of a cloud-based teacher-centered electronic platform, UNIO, as a form of educational technology to support the PBL in medicine process. One of the goals of such integration is to minimize lack of student interest, alienation and boredom that may influence the dynamics of PBL tutorial sessions and compromise active and collaborative learning. The main aim of the study is to focus on students' perceptions to the integration of UNIO within the PBL medical curriculum. The response rate of the student survey evaluating their perception to UNIO was average at almost $60 \%$, probably because it was not mandatory for students to respond, and there were no incentives offered to them. 


\section{Technical}

It is important to make sure that the technical equipment does not disrupt the group process. Technical problems sometimes interfered with the group activities, and in the "Technical" section of the survey, the relatively lowest scores on accessing the platform at campus may relate to occasionally poor network connectivity at campus, or untimely access to UNIO at the beginning of the tutorial sessions. Nevertheless, back-up measures were always available, such as the continuous technical support from the IT department for minimizing any disruptions in the e-learning process. We always had paper-based triggers as back - up, in order to ensure that the tutorial groups could function even if UNIO did not.

The positive lean of the responses indicates that many students consider UNIO as user friendly. It is important that interactive software have an easy format that allows the learner to focus on the substantive problem rather than the mechanics of use. UNIO's ease of navigation and user-friendly interface avoided distraction by technology during tutorial sessions. Such features in addition to ease of use, ease of access and interactivity are known to improve learners' satisfaction rates (Gibbons and Fairweather, 2000; Chumley-Jones, Dobbie, and Alford, 2002). The off-campus access response leaned in the positive direction, and this could be due to the cloud-based nature of UNIO platform, in which content can be freely accessed and used anywhere via Internet access. A unique feature to our electronic PBL experience with UNIO platform is the ease of access to content anytime from anywhere. This allowed students to retrieve their tutorial sessions with their accompanying trigger material and class annotations anytime of their clerk-ship years. Additionally the high level of organization of embedded content was highly appreciated by students who did not face any difficulty in accessing the required content.

\section{Effectiveness in PBL}

The largest area of agreement occurred on most items related to the effectiveness in PBL and support for student learning, with scores exceeding $60 \%$ in the original coding method and leaning with highest positive scores when the "Neutral" score was coded with " 0 ". This section mainly focuses on the employability of UNIO during the face-to-face in-class sessions. Most students believe that UNIO enhances group learning and group discussions. This could be a result of the network linkage between all group members, which ensured sufficient real-time interaction between all group members. Additionally, the digitization of both text triggers and media triggers and the projection of the scenario on the smartboard might have enhanced group focus and collaborative learning during tutorial sessions. This is in line with other studies that claim that the use of interactive whiteboards in the classroom support the discussions during face-to-face sessions (Lu, Lajoie and Wiseman, 2010) and does lead to increased student engagement during the learning process (Beeland, 2002).

The ability of mixing embedded content and annotations is a very powerful feature of UNIO, especially when taking notes or highlighting certain elements on radiology images, pathology slides as well as other forms of illustrations. When done collaboratively by the group members and the "Presenter" at the smartboard, it engages students. This was possible since the "Presenter" did not take on a teacher role in the group, nor became excluded from the group process. The Presenter can take notes on behalf of the class, move pages, and even embed extra content from the web, which is automatically broadcasted to all group members. Annotations related to the trigger were made of brainstorming words, learning issues and questions on each trigger page.

The web format of UNIO has other advantages: first, the web-based scenarios have a gradually unfolding quality, which sparked curiosity in students, and the gradual unfolding of new triggers kept students in a state of suspense. Second, it enables the use of multimedia, which together with the hypertext format, creates a more dynamic way of delivering triggers compared to the previously used paper-based cases. Multimedia like graphics, sound, animation and video can promote student intellectual engagement and attention-holding (Reeves, 1998), two cognitive constructs that are crucial for the PBL process. For instance, appropriate visual triggers when planned and delivered effectively can be engaging and stimulate group discussion (Tseng, Chiang and Husu, 2008). Interestingly, the results from the evaluation item addressing the effectiveness of UNIO in integrating media content within triggers showed favorable students' perception of the effectiveness of the visual media with which they engaged. This is not surprising as multimedia content in PBL is considered to be of greater realistic representation and authenticity than print material (Balslev et al., 2005 \& 2008; Kamin et al., 2003; Parkin and Dogra, 2000; Personn, Fyrenius and Bergdahl, 2010). 
Students seem to have been satisfied with the ability to embed content from the web into UNIO during tutorial sessions. Difficult concepts can be abstract and can only be comprehensible with a media presentation. When embedded, it is automatically broadcasted to and saved for all group members. For instance animations of physiological processes, 3D anatomical rotations and other concepts can be easily discussed during the tutorial session.

\section{Preparation for Exams}

There was an average response to the category of "Preparation for Exams". However, when considering embedded content, by the end of the pre-clerkship phase all students would have 92 health problems embedded in a structured and organized manner, making access to content easy. All content, whether annotations or embedded by the e-learning expert, the tutor or the students, is preserved for the students until their BSc. exam at the end of their pre-clerkship phase. This can minimize the amount of hard copy material that students have to deal with for preparation for their exams.

\section{Application}

Most of the students feel that application of UNIO did enhance their learning capacity during tutorials. This could be related to the proper organization of the material, the quality of the embedded media, which is superior to some paper-based counterparts. Students appreciated the Zoom feature since the larger displays helped them identify many features in microscopic displays, radiology imaging and others.

\section{Overall}

UNIO actively involved technology and multimedia tools to successfully implement PBL and support students' learning. Use of the customized electronic platform, UNIO, did not disrupt the group process or the PBL tutorial dynamics, retained the traditional face-to-face PBL for tutorials, and maintained the structure of our PBL traditional curriculum while extended the ability to use technology and multimedia. This is similar to Donnelly's (2010) blended PBL structure, which he defined as face-to-face tutorials with online support. Another important unique feature of this platform is the on-campus and off-campus access to organized course material, especially important is the availability of all annotations and content that was embedded during the tutorial sessions.

The results of our student survey suggest that the students were averagely satisfied with the integration of UNIO within their PBL sessions. The most frequent rating for all items was "Neutral", comprising $30 \%$ to $40 \%$ of responses for each item. The non-forced choice nature of the current survey may have contributed to the frequent "Neutral" response. When surveys include "Neutral" options, respondents sometimes tend to choose a neutral response because they do not want to exert the cognitive effort to form an opinion (Krosnick, 1999), or they might do so due to evasiveness (desire not to reveal one's true opinion), indecision (uncertainty about one's position), or indifference (lack of interest in an issue) (Baumgartner and Steenkamp, 2001). Some early research by Presser and Schuman (1980) found that typically between 10-20\% of respondents chose the neutral option when it was provided compared to the same survey when it was not. Accordingly, we analyzed the data further by only including the non-neutral responses with positive and negative coding. One may argue that this step decreased the respondent pool to around an average of 70 for each item, making the response rate out of 202 students effectively at almost 35\%. This may not be enough to represent the 202 students, but it does give an indication to the direction of responses without the "Neutral" option for each item.

One of the limitations of this study is the timing of the survey in relation to the units covered. Because the survey was conducted midway through the second year of $\mathrm{PBL}$ after completion of only two units, not all students may have been fully comfortable with the e-platform, due to diverse onset of exposure to e-learning for students, with relatively more recent integration of e-learning for some students than others. As such, we feel that student satisfaction is usually lower at the beginning because they have to adjust to the new method of learning while learning content at the same time (Chang and Tung, 2008).

Another limitation is the relatively low survey response rate with the average perceptions of this platform. There is a need for further directions to substantiate the effectiveness of this electronic platform in a PBL setting. It may be evaluation of UNIO midway through the units (after unit 5) and obtaining regular student feedback over a longer term. Other forms of evaluation may involve randomizing students into one of two 
treatment groups: those with paper-based tutorials, and those with the UNIO-based, or comparing academic performance through exam scores between pre-and post UNIO cohorts (Jenkinson, 2009) at CMMS.

\section{Competing Interests}

The authors report no conflicts of interest of financial or non-financial nature. The authors alone are responsible for the content and writing of this article.

\section{Funding}

This UNIO project was funded by the Arabian Gulf University in Bahrain.

\section{Authors' Contributions}

All authors contributed equally to the development of the survey used in this project. Dr. Rima Abdul Razzak and Mr. Arpan Stephen are responsible for the customization process of UNIO. Prof. Zuheir Hasan and Dr. Rima Abdul Razzak carried out the data analysis, write-up and editing of the manuscript.

\section{Ethics Approval}

Ethical approval for this project was granted by the Research and Ethics Committee at the College of Medicine and Medical Sciences at AGU.

\section{References}

Balslev, T., de Grave, W., Muijtjens, A.M.M., Eika, B., and Ssherpbier, A.J.A., 2005. Comparison of text and video cases in a postgraduate problem-based learning format. Medical Education, 39(11), pp.1086- 1092.

Balslev, T., de Grave, W., Muijtjens, A.M.M., Eika, B., and Ssherpbier, A.J.A., 2008. The development of shared cognition in paediatric residents analyzing a patient video versus a paper patient case. Advances in Health Science Education, 14(4), pp. $557-565$.

Barrows, H.S., 2002. Is it truly possible to have such a thing as PBL? Distance Education, 23(1), pp. $119-122$.

Barrows, H.S., and Tamblyn, R. M., 1980. Problem-based learning: An approach to medical education. New York, NY: Springer,

Baumgartner, H., and Steenkamp, J.B., 2001. Response styles in marketing research: a cross-national investigation. Journal of Marketing Research, 38, pp. $143-156$.

Beeland, W. D., 2002. Student engagement, visual learning and technology: can interactive whiteboards help? Action Research Exchange, 1(1).

Bridges, S., Botelho, M., Green, J. L., and Chau, A. C. M., 2012. Multimodality in problem-based learning (PBL): An interactional ethnography. In: Bridges, S.M., McGrath, C. and Whitehill, T. M., Problem-Based Learning in Clinical Education: The Next Generation, Springer.

Bridges SM, Botelho MG, Tsang PCS. PBL.2.0: Blended learning for an interactive, problem-based pedagogy. Medical Education. 2010; 44(11):1131.

Chang, S. C., and Tung, F.C., 2008. An empirical investigation of students' behavioral intentions to use the online learning course websites. British Journal of Educational Technology, 39(1), pp. $71-83$.

Chumley-Jones, H.S., Dobbie, A., and Alford, C.L., 2002. Web-based learning: sound educational method or hype? A review of the evaluation literature. Academic Medicine, 77 (10 Suppl), S86 - S93.

Donnelly, R., 2010. Harmonizing technology with interaction in blended problem-based learning. Computers and Education, 54(2), pp. $350-359$.

Gibbons, A., and Fairweather, P., 2000. Computer-based instruction. In: Tobias S, Fletcher J (Eds.). Training \& Retraining: A Handbook for Business, Industry, Government, and the Military (pp $410-442$ ). New York.

Harris, D.M., Ryan, K., and Rabuck, C., 2012. Using a high fidelity patient simulator with first-year medical students to facilitate learning of cardiovascular function curves. Advances in Physiology Education, 36, pp. $213-219$.

Hung, W., Jonassen, D.H., and Liu, R., 2008. Problem-based learning. In JM Spector, JG van Merrienboer, MD Merrill, and M Driscolls (Eds). Handbook on research on educational communications and technology, 3rd Ed. New York: Lawrence Erlbaum Associates.

Jenkinson, J., 2009. Measuring the effectiveness of educational technology: What are we attempting to measure? Electronic Journal of e-Learning, 7(3), pp. $273-280$.

$\mathrm{Jim}$, J. and Bridges, S.M., 2014. Educational technologies in problem - based learning in health sciences education: a systemic review. Journal of Medical Internet Research, 16(12), e251.

Kamin, C., O'Sullivan, P., Deterding, R., and Younger, M., 2003. A comparison of critical thinking in groups of third-year medical students in text, video, and virtual PBL case modalities. Academic Medicine, 78(2), pp. $204-2011$.

Koschmann, T., Kelson, A.C., Feltovich, P.J. and Barrows, H.S., 1996. Computer supported problem- based learning: A principled approach to the use of computers in collaborative learning. In T. Koschmann (Ed), CSCL: Theory and Practice, pp. 83 - 124. Mahwah, NJ: Lawrence Erlbaum Associates.

Krosnick, J.A., 1999. Survey research. Annual Review of Psychology, 50:1, pp. 537-567. 
Liaw, S.S., 2008. Investigating students' perceived satisfaction, behavioral intention, and effectiveness of e-learning: A case study of the Blackboard system. Computers \& Education, 51(2), pp. $864-873$.

Lu, H.P., and Chiou, M. J., 2010. The impact of individual differences on e-learning system satisfaction: A contingency approach. British Journal of Educational Technology, 41(2), pp. $307-323$.

Lu, J., Lajoie, S. P., and Wiseman, J., 2010. Scaffolding problem-based learning with CSCL tools. International Journal of Computer-Supported Collaborative Learning, 5(3), pp. 283-298.

Moust, J., Bouhuijs, P., and Schmidt, H., 2014. Introduction to problem-based learning: A guide for students. Groningen, Netherlands: Noordhoff Uitgevers B.V.

Parkin, A., and Dogra, N., 2000. Making videos for medical undergraduate teaching in child psychiatry: The development, use and perceived effectiveness of structured videotapes of clinical material for use by medical students in child psychiatry. Medical Teacher, 22(6), pp. $568-571$.

Personn, A-C., Fyrenius, A., and Bergdahl, B., 2010. Perspectives on using multimedia scenarios in a PBL medical curriculum. Medical Teacher, 32, pp. $766-772$.

Presser, S. and Schuman, H., 1980. The Measurement of a middle position in attitude surveys. Public Opinion Quarterly, 44(1), pp. $70-85$.

Price Kerfoot, B., Masser, B. A. and Hafler, J. P., 2005. Influence of new educational technology on problem-based learning at Harvard Medical School. Medical Education, 39(4), pp. $380-387$.

Reeves, T.,1998. The impact of media and technology in schools. Georgia: The Bertelsmann Foundation.

Savin-Baden, M., Gourlay, L., Tombs, C., Steils, N., Tombs, G. and Mawer, M., 2010. Situating pedagogies, positions and practices in immersive virtual worlds. Educational Research, 52(2), pp. $123-133$.

Savin-Baden, M., Tombs, C., Poulton, T., Conradi, E., Kavia, S., Burden, D., and Beaumont, C., 2011. An evaluation of implementing problem-based scenarios in an immersive virtual world. International Journal of Medical education, 2, pp. $116-124$.

Tseng, K., Chiang, F., and Husu, H., 2008. Interactive processes and learning attitudes in a web-based problem-based learning (PBL) platform. Computers in Human Behavior, 24, pp. $940-955$.

Verstegen, D., de Jong, N., van Berlo, J., Camp, A., Konings, K.D., van Merrienboer, J., and Donkers, J., 2016. How e-Learning can support PBL groups: A literature review. In S. Bridges et al (Eds.), Educational technologies in Medical Health and Health Sciences Education, Advances in Medical Education 5. Switzerland: Springer. $32{ }^{`} 1$ qew21 